\title{
Correction to: Intracellular hypoxia measured by F-18 fluoromisonidazole positron emission tomography has prognostic impact in patients with estrogen-receptor positive breast (BRCR-D17-00693)
}

Aya Asano ${ }^{1 \dagger}$, Shigeto Ueda ${ }^{2 \dagger}$, Ichiei Kuji ${ }^{3^{*}}$, Tomohiko Yamane ${ }^{3 \dagger}$, Hideki Takeuchi ${ }^{1}$, Eiko Hirokawa ${ }^{2}$, Ikuko Sugitani ${ }^{2}$, Hiroko Shimada ${ }^{2}$, Takahiro Hasebe ${ }^{4}$, Akihiko Osaki ${ }^{2}$ and Toshiaki Saeki ${ }^{2}$

\section{Correction}

After the publication of this article [1], we noticed that in Fig. 2, the survival curve images (C and $\mathrm{D}$, lower panel) were incorrect. The corrected Fig. 2 is presented below. The correction does not affect in any our results and conclusions.

* Correspondence: kuji@saitama-med.ac.jp

${ }^{\dagger}$ Aya Asano, Shigeto Ueda and Tomohiko Yamane contributed equally to this work.

${ }^{3}$ Department of Nuclear Medicine, Saitama Medical University International Medical Center, 1397-1 Yamane, Hidaka, Saitama 350-1241, Japan 

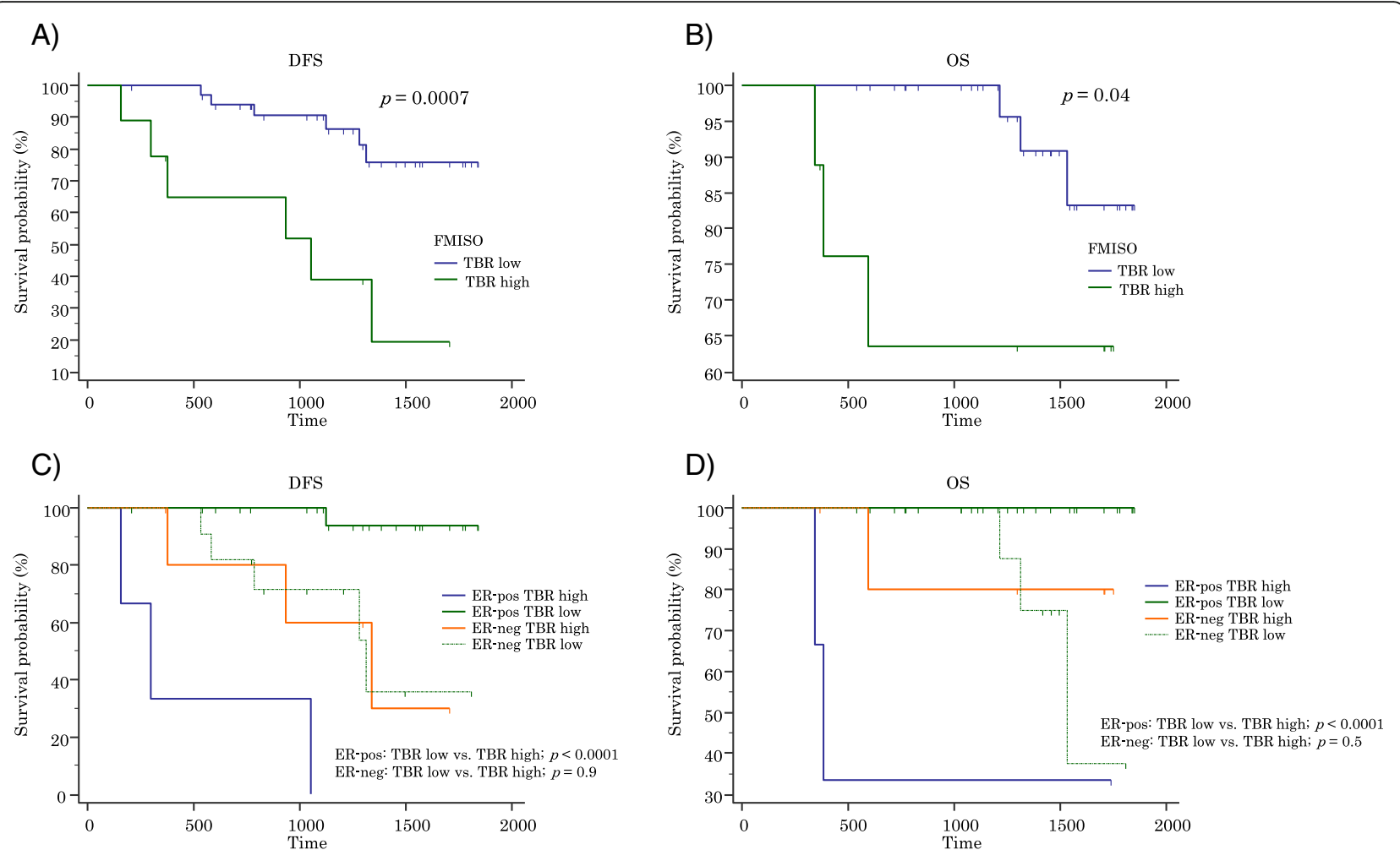

Fig. 2 Survival curves. a Disease-free survival (DFS). b Overall survival (OS). c DFS stratified by estrogen receptor (ER) status. d OS stratified by ER status. The tentative cutoff value of 1.48 separates tumors with higher ${ }^{18} \mathrm{~F}$-fluoromisonidazole tissue-to-blood ratio (TBR high) from those with lower ${ }^{18}$ F-fluoromisonidazole tissue-to-blood ratio (TBR low)

\section{Author details}

'Department of Breast Oncology, Saitama Medical University Hospital, 38 Morohongo, Moroyama-machi, Irumagun, Saitama 350-0451, Japan.

${ }^{2}$ Department of Breast Oncology, Saitama Medical University International Medical Center, 1397-1 Yamane, Hidaka, Saitama 350-1241, Japan.

${ }^{3}$ Department of Nuclear Medicine, Saitama Medical University International Medical Center, 1397-1 Yamane, Hidaka, Saitama 350-1241, Japan.

${ }^{4}$ Department of Pathology, Saitama Medical University International Medical Center, 1397-1 Yamane, Hidaka, Saitama 350-1241, Japan.

\section{Published online: 05 September 2018}

\section{Reference}

1. Asano A, Ueda S, Kuji I, Yamane T, Takeuchi H, Hirokawa E, Sugitani I,

Shimada H, Hasebe T, Osaki A, et al. Intracellular hypoxia measured by (18)F-

fluoromisonidazole positron emission tomography has prognostic impact in patients with estrogen receptor-positive breast cancer. Breast Cancer Res. 2018;20(1):78. 